\title{
LLNL-TR-471219
}

LAW RENCE LIVERMORE N A T IO N A L LABORATORY

Report on $241,242 A m(n, x)$ surrogate cross section measurement

J. T. Burke, J. J. Ressler, J. Gostic, R. A. Henderson, L. A. Bernstein, J. E. Escher, D. Bleuel, A. Kritcher, C. Matoon, N. D. Scielzo, M. A. Stoyer

February 18, 2011 
This document was prepared as an account of work sponsored by an agency of the United States government. Neither the United States government nor Lawrence Livermore National Security, LLC, nor any of their employees makes any warranty, expressed or implied, or assumes any legal liability or responsibility for the accuracy, completeness, or usefulness of any information, apparatus, product, or process disclosed, or represents that its use would not infringe privately owned rights. Reference herein to any specific commercial product, process, or service by trade name, trademark, manufacturer, or otherwise does not necessarily constitute or imply its endorsement, recommendation, or favoring by the United States government or Lawrence Livermore National Security, LLC. The views and opinions of authors expressed herein do not necessarily state or reflect those of the United States government or Lawrence Livermore National Security, LLC, and shall not be used for advertising or product endorsement purposes.

This work performed under the auspices of the U.S. Department of Energy by Lawrence Livermore National Laboratory under Contract DE-AC52-07NA27344. 


\section{Report on ${ }^{241,242} \mathrm{Am}(\mathrm{n}, \mathrm{x})$ surrogate cross section measurement}

J.T. Burke, J.J. Ressler, J. Gostic, L. A. Bernstein, D. Bleuel, J.E. Escher, R.A. Henderson, A. Kritcher, C. Matoon, N.D. Scielzo, M.A. Stoyer

\section{Objective:}

The main goal of this measurement is to determine the ${ }^{242} \mathrm{Am}(\mathrm{n}, \mathrm{f})$ and ${ }^{241} \mathrm{Am}(\mathrm{n}, \mathrm{f})$ cross sections via the surrogate ${ }^{243} \mathrm{Am}$;

\begin{tabular}{|l|l|}
\hline Reaction & Surrogate \\
\hline${ }^{242} \mathrm{Am}(\mathrm{n}, \mathrm{f})$ & ${ }^{243} \mathrm{Am}\left({ }^{3} \mathrm{He},{ }^{3} \mathrm{He}^{\prime} \mathrm{f}\right)$ \\
\hline${ }^{241} \mathrm{Am}(\mathrm{n}, \mathrm{f})$ & ${ }^{243} \mathrm{Am}\left({ }^{3} \mathrm{He}, \alpha \mathrm{f}\right)$ \\
\hline
\end{tabular}

Gamma-ray data was also collected for the purpose of measuring the (n,2n) crosssections. The experiment was conducted using the STARS/LIBERACE experimental facility located at the 88 Inch Cyclotron at Lawrence Berkeley National Laboratory the first week of February 2011. A description of the experiment and status of the data analysis follow.

\section{Design of experiment}

In order to obtain a reliable ${ }^{241,242} \mathrm{Am}(\mathrm{n}, \mathrm{x})$ cross sections we designed the experiment using the surrogate ratio technique to use a known actinide cross section to determine an unknown one. The surrogate reactions used for the ratio technique in this experiment were ${ }^{236} \mathrm{U}\left({ }^{3} \mathrm{He},{ }^{3} \mathrm{He} \mathrm{x}^{\mathrm{x}}\right)$ and ${ }^{236} \mathrm{U}\left({ }^{3} \mathrm{He}, \alpha \mathrm{x}\right)$ which are surrogates for ${ }^{235} U(n, x)$ and ${ }^{234} U(n, x)$ respectively. The surrogate ratio technique measures known and unknown particle-fission ( $p-f)$ or particle-gamma $(p-\gamma)$ reaction spectra as a function of energy. The resulting $p-f$ or $p-\gamma$ coincidence spectra are then divided by one another and multiplied by the known cross section to determine the unknown cross section of interest. For example the ${ }^{242} \mathrm{Am}(\mathrm{n}, \mathrm{f})$ cross section will be determined by

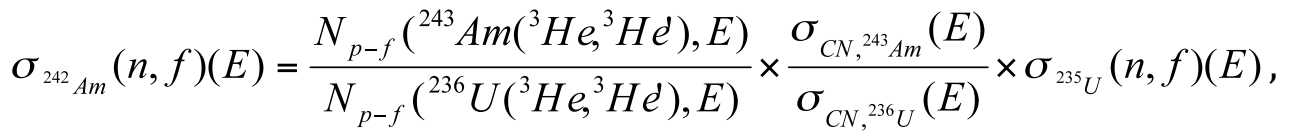

where $\mathrm{N}_{\mathrm{p}-\mathrm{f}}\left({ }^{243} \mathrm{Am}\left({ }^{3} \mathrm{He},{ }^{3} \mathrm{He}^{\prime}\right), \mathrm{E}\right)$ and $\mathrm{N}_{\mathrm{p}-\mathrm{f}}\left({ }^{236} \mathrm{U}\left({ }^{3} \mathrm{He},{ }^{3} \mathrm{He}\right), \mathrm{E}\right)$ are the number of ${ }^{243} \mathrm{Am}$ and ${ }^{236} \mathrm{U}$ particle-fission coincidence events (corrected for experimental conditions) at a given energy, $\sigma_{\mathrm{CN}}(\mathrm{E})$ are the compound nuclear formation cross sections using the neutron-induced reactions, and $\sigma^{235} \mathrm{U}(\mathrm{n}, \mathrm{f})(\mathrm{E})$ is the known energy dependent $235 \mathrm{U}$ cross section.

\section{Targets}

For this experiment, ${ }^{243} \mathrm{Am}$ targets were fabricated by Julie Gostic and Roger Henderson at LLNL. The ${ }^{236} \mathrm{U}$ target from the FY10 effort was also used.

The ${ }^{243} \mathrm{Am}$ material was electroplated onto $100 \mu \mathrm{g} / \mathrm{cm}^{2}$ thick carbon foils, using the electroplating set-up designed last year fiscal year for this project. The ${ }^{243} \mathrm{Am}$ and ${ }^{236} \mathrm{U}$ targets were alpha counted to establish their exact thickness, as shown in Fig. 2 . The activity of the ${ }^{243} \mathrm{Am}$ target was $29 \mu \mathrm{Ci}$, yielding an areal density of $115 \mu \mathrm{g} / \mathrm{cm}^{2}$ and the ${ }^{236} \mathrm{U}$ target was $322 \mu \mathrm{g} / \mathrm{cm}^{2}$. In the ${ }^{236} \mathrm{U}$ target, a minor contribution from ${ }^{234} \mathrm{U}$ is observed at a low level $\left(<1 \mu \mathrm{g} / \mathrm{cm}^{2}\right)$. 


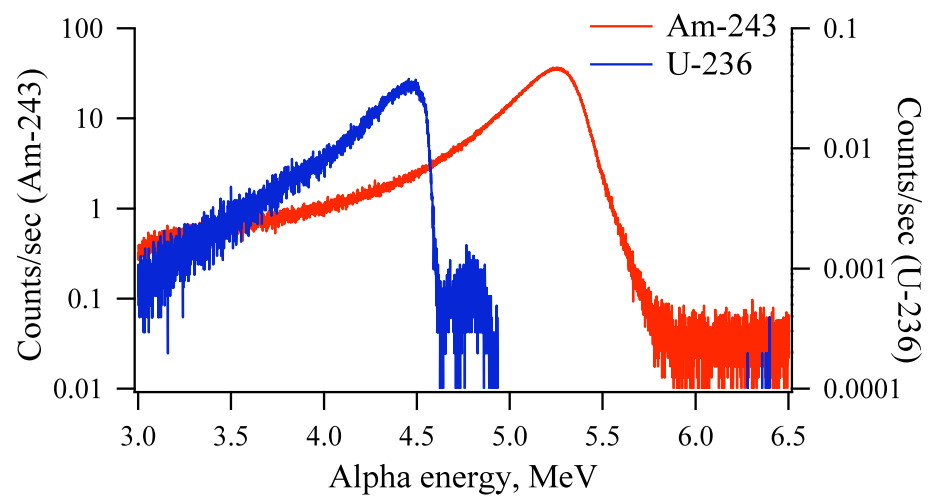

Figure 2. Alpha spectra from the ${ }^{243} \mathrm{Am}$ and ${ }^{236} \mathrm{U}$ targets used to determine the target areal densities and also identify any contaminants present in the target. The counting period was $3.8 \mathrm{~min}$ and 2.8 hours for the ${ }^{243} \mathrm{Am}$ and ${ }^{236} \mathrm{U}$ targets, respectively. The peak at $4.8 \mathrm{MeV}$ in the ${ }^{236} \mathrm{U}$ target spectra is attributed to ${ }^{234} \mathrm{U}$.

\section{Data Analysis}

The analysis of the experimental data has begun. Initial energy calibrations of the silicon detector elements (telescope and fission detector) have been completed and particle identification plots have been made; an example is shown in Fig. 3. The energy calibration will be refined to accommodate any shifts that occurred during the experimental period.

The particle-fission timing spectrum has been generated and used to determine the prompt and random particle-fission spectra. The particle identification and ray-trace cuts have been made to define particles originating from the target (not scattered beam from collimation). Combining all above elements, the data sort code has been run to generate the preliminary particle-fission coincident spectra needed to obtain the fission cross section from the Am and U targets used during this experiment, as shown in Fig. 4. 


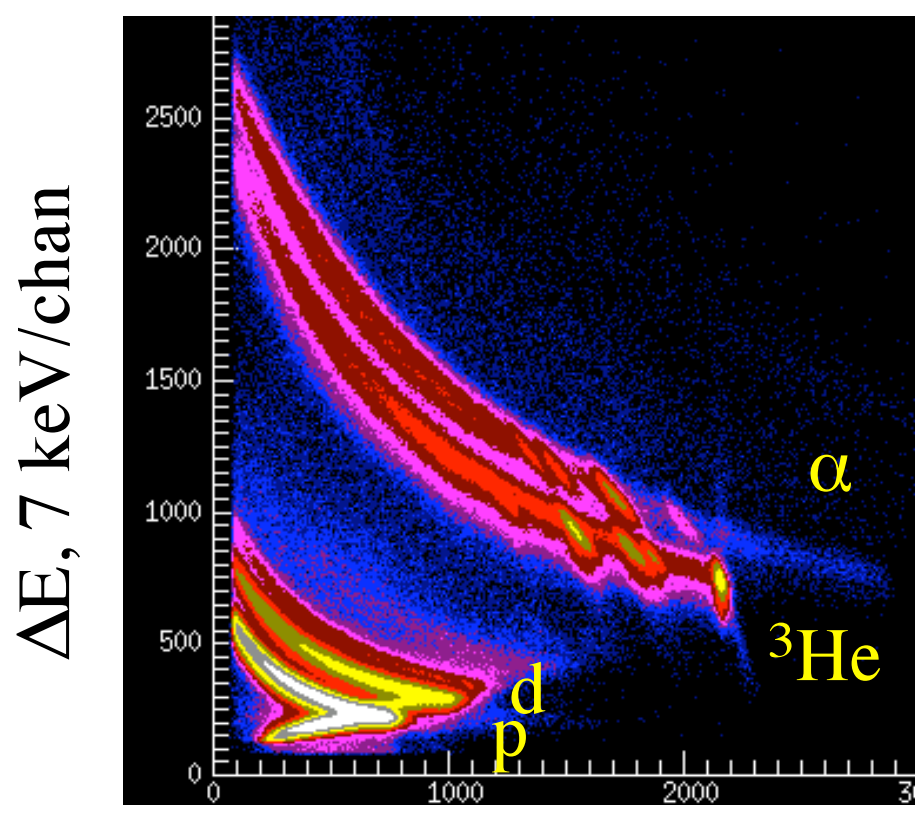

\section{E, $20 \mathrm{keV} / \mathrm{chan}$}

Figure 3. Particle identification plot for $49 \mathrm{MeV}^{3} \mathrm{He}$ on ${ }^{243} \mathrm{Am}$. This plot is used to select the scattered ${ }^{3} \mathrm{He}$ and alpha particles to create an energy dependent particlefission coincidence spectrum. Also shown are proton (p) and deuteron (d) out channels.

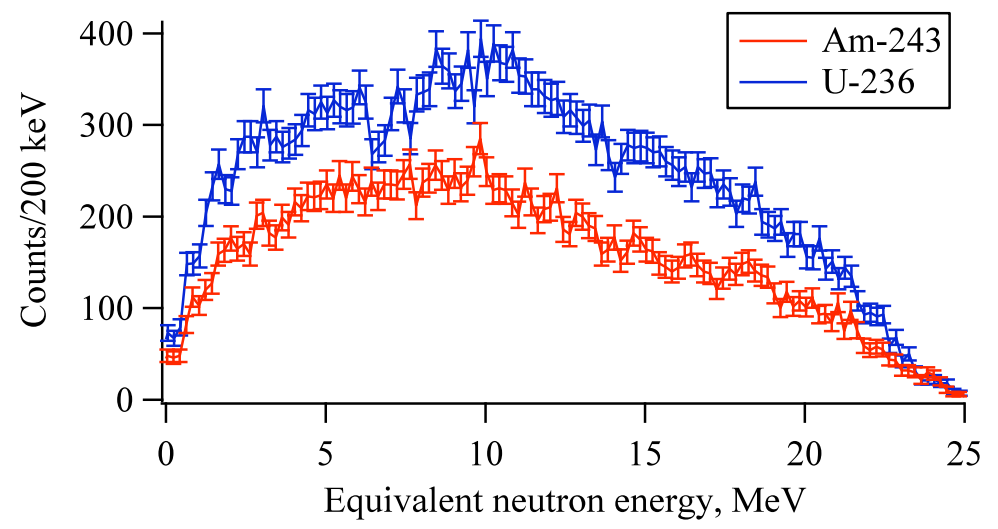

Figure 4. Preliminary ${ }^{3} \mathrm{He}$ particle-fission coincidence spectra from ${ }^{243} \mathrm{Am}$ and ${ }^{236} \mathrm{U}$ targets taken during the February 2011 experiment. Spectra are representative; only a subset (less than 50\%) of the total data acquired is shown.

\section{Work to complete}

We will continue to refine the data analysis of the fission cross-section and prepare the results for publication and for inclusion in the nuclear databases. We will also examine the quality and quantity of the data. 


\section{Collaborators}

For this experiment, we collaborated with our colleagues, students and postdocs from the University of Richmond, Rutgers University, St. Mary's University, the University of California Berkeley, and Lawrence Berkeley National Laboratory.

\section{Acknowledgements}

The authors thank the 88-Inch Cyclotron operations and facilities staff for the support of this study. We would also like to thank the Department of Energy's NNSA, Office of Nonproliferation Research and Development (NA-22), for financial support. This work was performed under the auspices of the U.S. Department of Energy under contract numbers DE-AC52-07NA27344 (LLNL) and DE-AC02-05CH11231 (LBNL). 